\title{
STATUS OF R\&D ON A SUPERCONDUCTING HELICAL UNDULATOR FOR THE ILC POSITRON SOURCE*
}

Y. Ivanyushenkov\#, E. Baynham, T. Bradshaw, A. Brummitt, S. Carr, A. Lintern, J. Rochford STFC Rutherford Appleton Laboratory, Chilton, Didcot, Oxfordshire OX11 0QX, UK

J.A. Clarke+, O.B. Malyshev+, D.J. Scott+, B.J.A. Shepherd+

STFC ASTeC Daresbury Laboratory, Daresbury, Warrington, Cheshire WA4 4AD, UK

I.R. Bailey+, P. Cooke, J.B. Dainton+, L. Malysheva+

Department of Physics, University of Liverpool, Oxford St., Liverpool, L69 7ZE, UK

D.P. Barber+

DESY-Hamburg, Notkestraße 85, 22607 Hamburg, Germany

G.A. Moortgat-Pick+

Institute of Particle Physics Phenomenology, University of Durham, Durham DH1 3LE, UK 


\title{
STATUS OF R\&D ON A SUPERCONDUCTING HELICAL UNDULATOR FOR THE ILC POSITRON SOURCE*
}

\author{
Y. Ivanyushenkov", E. Baynham, T. Bradshaw, A. Brummitt, S. Carr, A. Lintern, J. Rochford \\ STFC Rutherford Appleton Laboratory, Chilton, Didcot, Oxfordshire OX11 0QX, UK \\ J.A. Clarke ${ }^{+}$, O.B. Malyshev ${ }^{+}$, D.J. Scott ${ }^{+}$, B.J.A. Shepherd ${ }^{+}$ \\ STFC ASTeC Daresbury Laboratory, Daresbury, Warrington, Cheshire WA4 4AD, UK \\ I.R. Bailey ${ }^{+}$, P. Cooke, J.B. Dainton ${ }^{+}$, L. Malysheva ${ }^{+}$ \\ Department of Physics, University of Liverpool, Oxford St., Liverpool, L69 7ZE, UK \\ D.P. Barber $^{+}$ \\ DESY-Hamburg, Notkestraße 85, 22607 Hamburg, Germany

\section{G.A. Moortgat-Pick ${ }^{+}$} \\ Institute of Particle Physics Phenomenology, University of Durham, Durham DH1 3LE, UK
}

\section{Abstract}

An undulator based positron source is a baseline for the International Linear Collider (ILC). The HeLiCal collaboration in the UK is carrying out an R\&D programme on a short period superconducting helical undulator with the goal to develop modelling, measuring and manufacturing techniques. Several undulator prototypes have been built and successfully tested. This paper summarizes the results of the $R \& D$ phase of the project.

\section{INTRODUCTION}

The work of the HeLiCal collaboration is focused on the development of a superconducting undulator which meets the specifications for operation in the ILC (500 $\mathrm{GeV} e^{+} e^{-}$interactions in the first stage).

Following selection of superconducting technology for the ILC undulator in 2005, the collaboration started a R\&D programme to develop the short-period superconducting helical undulator. At this stage of the project, several short prototypes with lengths 300 to 500 $\mathrm{mm}$ were built and successfully tested. As a result of the R\&D phase, the technology was developed which allowed us to achieve the parameters required for the ILC undulator and to proceed to build a full scale 4-m long undulator module.

The outcome of the R\&D phase, including design, construction and test results of the superconducting prototypes are presented in this paper.

\footnotetext{
* Work supported by the Commission of the European Communities under the $6^{\text {th }}$ Framework Programme "Structuring the European Research Area", contract number RIDS-011899.

\#Y.Ivanyushenkov@rl.ac.uk

+ Cockcroft Institute, Daresbury Laboratory, Warrington, Cheshire WA4 4AD, UK.
}

\section{ILC UNDULATOR PARAMETERS}

The requirements for the ILC helical undulator have been discussed at the ILC Accelerator Workshops and at the Global Design Effort Meetings and are presented in the ILC Reference Design Report [1]. They are listed in the following table.

Table 1: ILC Undulator Parameters

\begin{tabular}{|l|l|}
\hline Electron Drive Beam Energy & $150 \mathrm{GeV}$ \\
\hline Photon Energy (1 $1^{\text {st }}$ harmonic cutoff) & $10.06 \mathrm{MeV}$ \\
\hline Photon Beam Power & $131 \mathrm{~kW}$ \\
\hline Undulator Type & helical \\
\hline Undulator Period & $11.5 \mathrm{~mm}$ \\
\hline Undulator Strength & 0.92 \\
\hline Field on Axis & $0.86 \mathrm{~T}$ \\
\hline Beam Aperture & $5.85 \mathrm{~mm}$ \\
\hline Undulator Length & $147 \mathrm{~m}$ \\
\hline
\end{tabular}

\section{SUPERCONDUCTING UNDULATOR R\&D}

\section{Aim of $R \& D$ Phase}

In 2004 the HeLiCal collaboration launched an extensive $R \& D$ programme with the goal of developing construction techniques applicable to manufacture a $2 \mathrm{~m}$ long superconducting helical undulator section, which can be used to build a full-scale undulator module for the ILC positron source. This phase of the project is now complete, the group is currently working on the design and manufacture of the first 4-m long undulator module. 


\section{Magnetic Modelling}

Intensive magnetic modelling was carried out, as a part of the R\&D programme, in order to select the winding geometry of the undulator.

More information on the magnetic modelling can be found in [2].

\section{Fabrication $R \& D$}

An extensive R\&D programme has been launched to develop fabrication techniques suitable for producing 2 $\mathrm{m}$ long sections of short-period helical undulators. The issues of machining undulator formers with a precision of $50 \mu \mathrm{m}$ or better, incorporating a beam pipe into the former, developing winding and vacuum impregnation techniques were addressed.

\section{SHORT UNDULATOR PROTOTYPES}

In order to test the techniques developed during the manufacture R\&D, 5 short undulator prototypes with a length of $300 \mathrm{~mm}$ and $500 \mathrm{~mm}$ have been built. The final prototype 5 was re-wound and re-impregnated with an improved technique and tested as prototype 5'. Parameters of the short prototypes built and tested, are listed in Table 2.

Prototypes (Fig. 1) are wound onto the formers such that the windings form a double helical winding with currents in opposite directions. Some details of winding technique are described in [3]. Prototypes 1- 4 were wound with a superconducting wire having a copper-tosuperconductor ratio of 1.35:1 while the final prototypes 5 and 5' use wire with the ratio of 0.9:1, this allowed for an increase in the operation current. The superconducting wires are glued into a ribbon which is used to wind undulators on a specially developed winding machine.

Prototypes 1 and 2 have a period of $14 \mathrm{~mm}$ and magnetic bore of $6 \mathrm{~mm}$ and are wound onto aluminium formers. Prototypes 3 and 4 have a shorter period (12 $\mathrm{mm}$ ) and differ only in the former material ( aluminium and soft iron respectively), these were used to study the effect of magnetic material and to compare the measured field with the magnetic modelling results. Prototype 5 is a short version of the final geometry selected for the full scale prototype and it was used to check manufacturing technique and winding geometry before building the longer undulator sections required for the first full-scale undulator module. Unlike prototypes 1-3 where the double helical groove was cut onto the bored former rod, the formers of the prototypes 4 and 5 were assembled by mounting two iron springs onto the copper bore tube. This technique has been adopted for the fabrication of $2-\mathrm{m}$ long undulator sections.

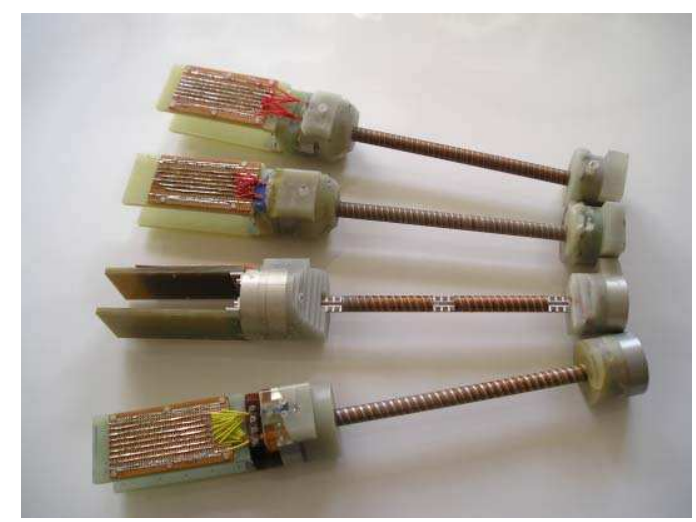

Figure 1: Prototypes 1 to 4 .

The quality of the winding technique was checked by sectioning of prototype 2 where the actual winding geometry was measured. The cross section of winding is shown in Fig. 2.

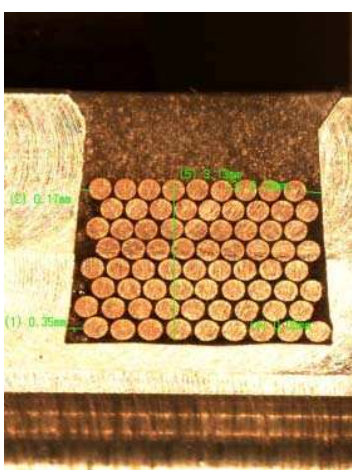

Figure 2: Prototype 2 winding cut.

Table 2: Parameters of Short Prototypes

\begin{tabular}{|c|c|c|c|c|c|c|}
\hline Parameter & Prototype 1 & Prototype 2 & Prototype 3 & Prototype 4 & Prototype 5 & Prototype 5' \\
\hline Prototype goal & $\begin{array}{c}\text { Winding } \\
\text { technique } \\
\text { verification }\end{array}$ & $\begin{array}{c}\text { Check effect of } \\
\text { mechanical } \\
\text { tolerances }\end{array}$ & $\begin{array}{l}\text { Prototype with } \\
\text { reduced period }\end{array}$ & $\begin{array}{l}\text { Check effect of } \\
\text { iron }\end{array}$ & $\begin{array}{l}\text { Prototype with } \\
\text { the final period }\end{array}$ & $\begin{array}{c}\text { Quench study } \\
\text { with improved } \\
\text { impregnation }\end{array}$ \\
\hline Length & $300 \mathrm{~mm}$ & $300 \mathrm{~mm}$ & $300 \mathrm{~mm}$ & $300 \mathrm{~mm}$ & $500 \mathrm{~mm}$ & $500 \mathrm{~mm}$ \\
\hline Former material & Aluminium & Aluminium & Aluminium & Iron & Iron & Iron \\
\hline Winding period & $14 \mathrm{~mm}$ & $14 \mathrm{~mm}$ & $12 \mathrm{~mm}$ & $12 \mathrm{~mm}$ & $11.5 \mathrm{~mm}$ & $11.5 \mathrm{~mm}$ \\
\hline Winding bore & $6 \mathrm{~mm}$ & $6 \mathrm{~mm}$ & $6 \mathrm{~mm}$ & $6 \mathrm{~mm}$ & $6.35 \mathrm{~mm}$ & $6.35 \mathrm{~mm}$ \\
\hline Magnet bore & $4 \mathrm{~mm}$ & $4 \mathrm{~mm}$ & $4 \mathrm{~mm}$ & $4.5 \mathrm{~mm}$ & $5.23 \mathrm{~mm}$ & $5.23 \mathrm{~mm}$ \\
\hline $\begin{array}{l}\text { Superconducting } \\
\text { wire }\end{array}$ & $\begin{array}{l}\mathrm{Cu}: \mathrm{SC} \\
1.35: 1 \\
\end{array}$ & $\begin{array}{l}\mathrm{Cu}: \mathrm{SC} \\
1.35: 1\end{array}$ & $\begin{array}{l}\mathrm{Cu}: \mathrm{SC} \\
1.35: 1\end{array}$ & $\begin{array}{l}\mathrm{Cu}: \mathrm{SC} \\
1.35: 1\end{array}$ & $\begin{array}{c}\mathrm{Cu}: \mathrm{SC} \\
0.9: 1\end{array}$ & $\begin{array}{c}\mathrm{Cu}: \mathrm{SC} \\
0.9: 1\end{array}$ \\
\hline Winding & $\begin{array}{c}\text { 8-wire ribbon, } \\
8 \text { layers }\end{array}$ & $\begin{array}{c}9 \text {-wire ribbon, } \\
8 \text { layers }\end{array}$ & $\begin{array}{c}\text { 7-wire ribbon, } \\
8 \text { layers }\end{array}$ & $\begin{array}{c}\text { 7-wire ribbon, } \\
8 \text { layers }\end{array}$ & $\begin{array}{c}\text { 7-wire ribbon, } \\
8 \text { layers }\end{array}$ & $\begin{array}{c}\text { 7-wire ribbon, } \\
8 \text { layers }\end{array}$ \\
\hline
\end{tabular}


After winding all the prototypes were vacuum impregnated with epoxy resin. In prototypes 1-4 the end regions were loaded with glass micro spheres to reduce the volumes of clear resin and eliminate cracking. This is evident from the tests of the prototypes 5 and 5'. The test of prototype 5 which had no micro spheres in the resin, showed visible cracking after cool down whilst the prototype 5 ' impregnated with micro spheres, did not.

\section{R\&D PHASE RESULTS}

\section{Field Achieved}

Field profile was measured by using a Hall probe moved by a stepper motor through the bore of the undulator under the control of a PC running LabVIEW. The value of radial component of magnetic field was measured in steps of $0.1 \mathrm{~mm}$ over the length of the magnet. In some cases the field was measured in an orthogonal plane as well.

A typical field profile is shown in Fig.3.

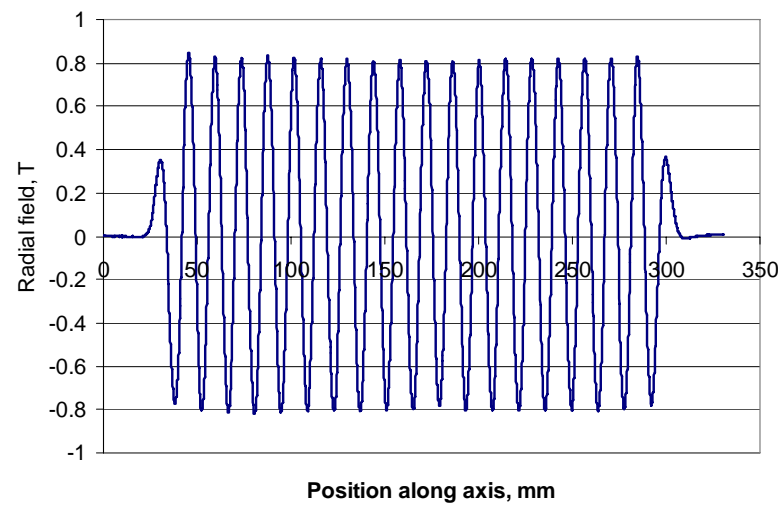

Figure 3: Profile of the axial component of the magnetic field on the undulator axis measured for prototype 1 .

The homogeneity of the field (peak-to-peak) was at the level of $1 \%$. The field quality depends on the former geometrical tolerances. A study made on prototype 2, indicated that the field changed in value by $2 \%$ for every $100 \mu \mathrm{m}$ deviation from the nominal winding bore size of $6 \mathrm{~mm}$. The achieved values of the field for the prototypes are listed in the following table.

Table 3: Measured Field for Prototypes

\begin{tabular}{|l|c|c|c|c|c|}
\hline Prototype & 1 & 2 & 3 & 4 & 5 \\
\hline Period, mm & 14 & 14 & 12 & 12 & 11.5 \\
\hline $\begin{array}{l}\text { Field at test } \\
\text { current, T }\end{array}$ & 0.8 & 0.9 & 0.53 & 0.96 & 0.82 \\
\hline Test current, A & 220 & 220 & 200 & 200 & 200 \\
\hline Quench current, A & - & - & - & 230 & 315 \\
\hline
\end{tabular}

The results from the prototype 5 test indicated that the nominal field of $0.86 \mathrm{~T}$ required by the ILC undulator specification could be reached at an operation current of
216 A which was far below the measured quench current of $315 \mathrm{~A}$.

\section{Quench Study}

The quench current was measured for prototypes 4,5 and 5', see Table 2. It is found that prototype 4 wound with $0.44 \mathrm{~mm}$ Vacryflux superconducting wire with 1.35:1 copper-to-superconductor ratio, quenches at $230 \mathrm{~A}$ while the quench current of prototype 5 wound with Supercon $0.44 \mathrm{~mm}$ wire with 0.9:1 $\mathrm{Cu}$-to-SC ratio is 315 A .

The prototype 5 quench study indicated a training process for this prototype which was eliminated by an improved impregnation technique in the prototype $5^{\prime}$ as shown in Fig. 4 and discussed previously.

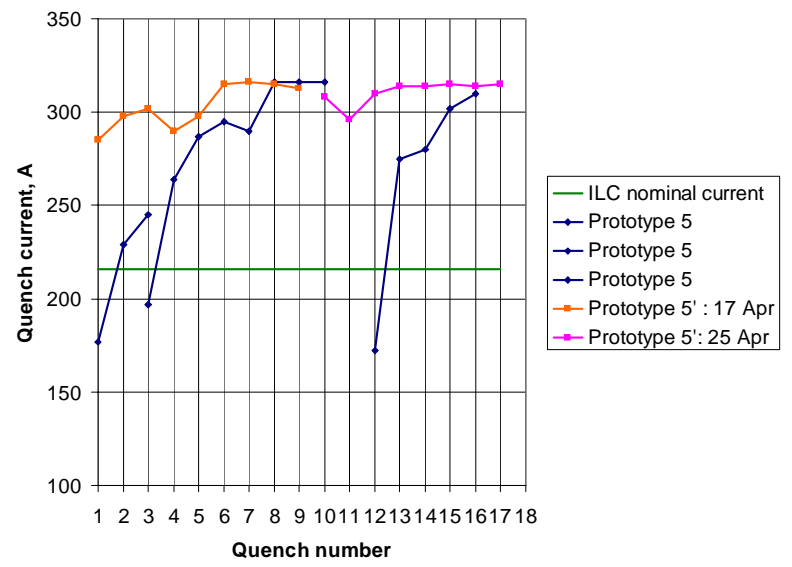

Figure 4: Quench history for prototypes 5 and 5'.

\section{CONCLUSION}

The HeLiCal group has completed the initial phase of an $R \& D$ programme aimed at developing the manufacturing techniques applicable to building a fullscale undulator module which meets the specifications for operation in the ILC positron source.

Through the technology development programme, several short prototypes have been built and successfully tested giving a clear experimental confirmation that the design field required for the ILC positron source undulator can be achieved.

\section{REFERENCES}

[1] International Linear Collider Reference Design Report, ILC-Report-2007-01, April, 2007.

[2] J. Rochford et al., "Magnetic Modelling of a Short Period Superconducting Helical Undulator for the ILC Positron Source", Proceedings of EPAC 2006, Edinburgh, p.840.

[3] Y. Ivanyushenkov et al., "Development of a Superconducting Helical Undulator for a Polarised Positron Source", PAC05, Knoxville, May 2005, p. 2295 